\title{
Iatrogenic Damage to the Periodontium Caused by Laser: An Overview
}

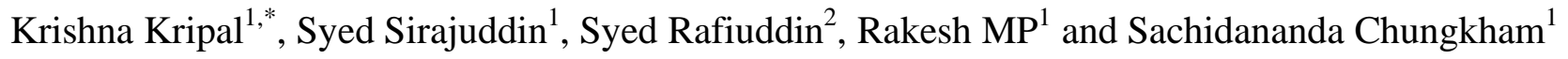 \\ ${ }^{l}$ Department of Periodontology, Rajarajeswari Dental College \& Hospital, Bangalore-560074.Karnataka, India; \\ ${ }^{2}$ Department of Orthodontics, Sri Hasanamba Dental College and Hospital, Hassan, Karnataka, India
}

\begin{abstract}
Lasers have been used in dentistry since 1994 to treat a number of dental problems. A variety of lasers are now available for use in dentistry. Once stated as an intricate technology with restricted usage in clinical dentistry, there is a growing awareness of the usefulness of lasers in the armamentarium of the modern dental practice, where they can be used as an adjunct or alternative to various long-standing approaches.
\end{abstract}

Keywords: Electrosurgery, iatrogenic damage, laser, modern dentistry, types of laser.

\section{INTRODUCTION}

One of the key advantages for using dental lasers (Fig. 1) is the proficiency to precisely interact and, in some cases, remove a small number of cell layers at a time.

In dentistry, scalpel, electro surgery and laser are the three frequently used procedures for cutting oral soft tissues. All of these procedures work. However, there are differences in hemostasis, healing time, cost of instruments, width of the cut, anesthetic required and unpleasant features, such as smoke production, the odor of burning flesh and adverse taste. However, laser has established noteworthy commercial importance in the past few years.

For soft tissue surgery, the scalpel and the conventional electro-surgery unit are the instruments of choice. However, lasers are adjunct to conventional surgical systems. Scalpels have been used for many years because of their ease of use, precision, and negligible injury to the adjacent tissues. But scalpels cannot provide the required hemostasis for use on highly vascular tissues [1].

The generation of a coagulated tissue layer along the walls of the laser incision is the characteristic difference between a laser incision and a scalpel incision [2]. Some degree of tissue vaporization and thermal necrosis of the surrounding tissue is produced with laser-tissue interactions [3]. This may impede wound healing and graft take, and reduce the tensile strength if the zone of thermal damage is not kept to a minimum [4].

\section{ADVANTAGES OF LASER OVER SCALPEL SURGI- CAL PROCEDURES OF THE ORAL TISSUES}

Advantages include better precision, a comparatively bloodless surgical and postsurgical course, sterilization of the surgical area, insignificant swelling and scarring, coagulation, vaporization, and cutting, nominalor no suturing, and

*Address correspondence to this author at the Department of Periodontology, Rajarajeswari Dental College and Hospital, Mysore road, Bangalore560074, Karnataka, India; Mobile: +919632597504;

E-mail: kripalkrishna@yahoo.com minimal postsurgical pain [5]. Various studies have confirmed that laser surgery can be performed safely by using parameters which protect tooth structures and the underlying bone [6].

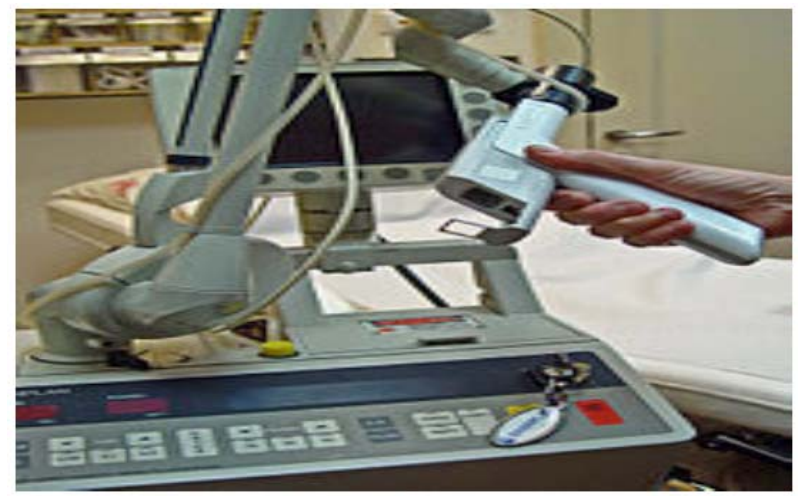

Fig. (1). A 40 watt CO2 laser used for soft-tissue laser surgery.

The factors that regulate the early tissue effects depend on the laser wavelength, laser power, the available laser waveform (continuous wave, chopped, and pulsed beams), tissue optical properties, and tissue thermal properties [7].

Lasers cannot provide the same proficiency and effectiveness as a scalpel for many diverse oral procedures although certain lasers are ideal for specific oral procedures. Electrosurgery units have the disadvantage of causing greater thermal injury and muscle fasciculation' salthough they produce adequate hemostasis. Studies have reported delayed healing for electrosurgery wounds when compared with scalpel wounds [8].

Histologic events resulting from soft-tissue incisions with different $\mathrm{CO} 2$ lasers have observed that the use of the constant wave mode results in a greater damage to the collateral tissues (Fig. 2). Higher the average power higher is the depth of incision. Incision width and collateral damage are the outcomes of complex interactions between various laser parameter variables; Incision shape and width are strongly mode-dependent. The $\mathrm{CO} 2$ mode produces reasonably wide, 


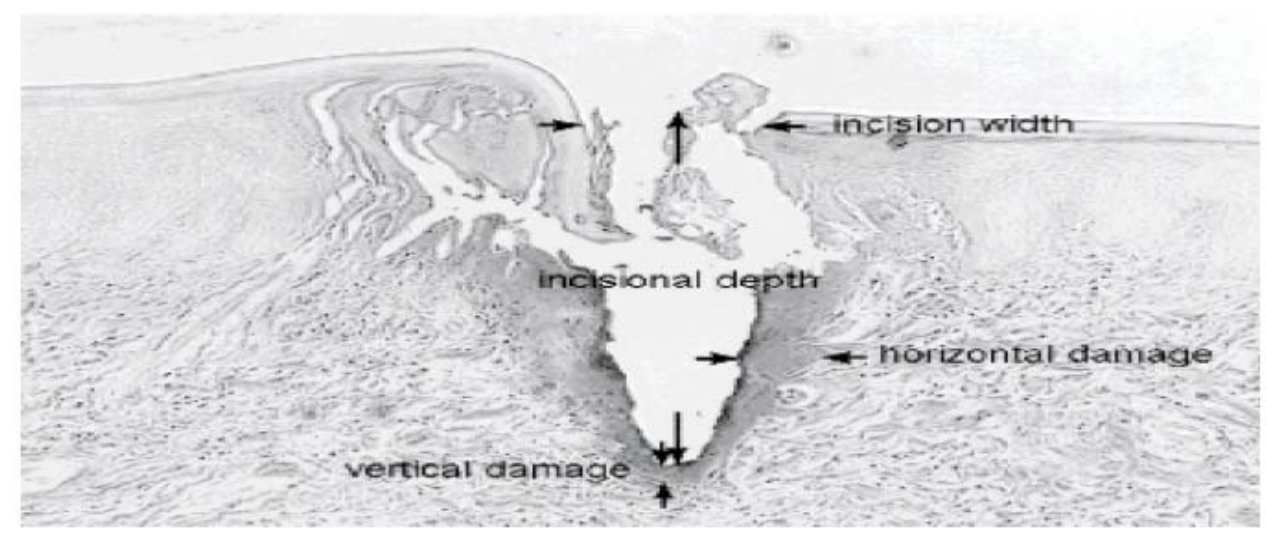

Fig. (2). Incisional and collateral effects of diode laser in oral soft tissue.

straight-sided incisions. Therefore, this mode can cut or ablate large amounts of tissue. Comparable incisions in depth can be achieved equally quickly and efficiently at lower average powers with the super pulse mode [9].

Damage to soft tissue by $\mathrm{CO} 2$ laser may be categorized into three zones- The first zone is an outer layer consisting of carbonized material, the second zone is a zone of vacuolation where cavities have been formed by the explosive conversion of water to steam and the third zone is the coagulated zone which has been formed at temperatures below 100 degrees C.

A model is proposed which predicts the maximum (i.e. dynamic equilibrium) depth of each of these layers. The maximum effective thickness of the vacuolated zone is reported to depend upon the absorption coefficient of the tissue for $\mathrm{CO} 2$ laser radiation, but not on the incident irradiance. The thickness of the carbonized zone is shown to decrease with increasing radiance, and the depth of the sub-boiling coagulated zone also decreases with increasing irradiance, but depends to some extent on the penetration of laser radiation through the soft tissue [10].

Slot and colleagues [11], reviewed 8 studies of the additional effect of pulsed $\mathrm{Nd}: Y A G$ laser in nonsurgical periodontal therapy. Of these, 2 studies compared the Nd:YAG laser alone with SRP; 1 compared lasers with ultrasonic instrumentation and 1 with sham therapy (inserting the fiber tip into the pocket without irradiation); 4 compared laser therapy plus SRP with SRP alone. In 1 study, 4 groups measured the effect of order of treatment (laser alone, laser followed by SRP, SRP followed by laser and SRP alone). None of the studies found that laser therapy was more effective than traditional instrumentation with ultrasonic or hand instruments in terms of plaque reduction, pocket reduction, decreased bleeding or gain in clinical attachment levels.

Although studies have reported that soft tissue wounds of laser heal faster and produce less scar tissue than those from scalpel surgery, this is not established in the literature, in either histologic studies or clinical trials. However, studies of $\mathrm{CO} 2$ lasers report that healing is primarily slower than after scalpel surgery [12]. In addition, after exposure to Nd:YAG lasers, the activity of fibroblasts, the cells responsible for producing new connective tissue attachment in wound healing, is significantly delayed [12].
Lasers have been promoted for clinical crown lengthening procedure for esthetic and prosthetic reasons, without reflecting the gingival flap. However, the use of lasers for closed-flap crown lengthening is not supported by any randomized controlled trials or cohort studies. With the use of $\mathrm{CO} 2$ and Nd:YAG lasers, Thermal side effects like melting, cracking and carbonization of the root-have been reported [13].

Subgingival curettage, with or without a dental laser, was originally intended to remove diseased pocket lining and to promote new connective tissue attachment to the root [14]. It has often been performed as a closed procedure in combination with scaling and root planing (SRP). Laser does not permit improved access for debridement or the enhanced visibility required to achieve complete mechanical removal of plaque, calculus and bacterial biofilm. Studies have interpreted that, irrespective of the method used (lasers, ultrasonics or hand instruments), curettage has no added benefit over SRP alone and, thus, has no reasonable application during active therapy for chronic periodontitis [15].

The statement supporting that lasers sterilize periodontal pockets [16] and, hence, stimulate reattachment of previously diseased connective tissue to root surfaces is equally weak. Decrease in periodontal pathogens itself is an inadequate measure of success. The gold standard in defining effectiveness of nonsurgical periodontal treatment is gain in clinical attachment level. Although there is enough evidence that laser energy can reduce or remove bacterial plaque, probing depths and levels of subgingival microbes are significant only if they are related with an increase in the degree of clinical attachment.

\section{LASER ENERGY AND TISSUE TEMPERATURE}

The principle outcome of laser energy is "photo thermal" (i.e, the conversion of heat energy into light energy). This thermal effect of laser energy depends on the degree of rise in temperature and the resultant response of the interstitial and intracellular water.

The rate of rise in temperature plays a significant role in this effect and is dependent on several factors, such as cooling of the surgical site and the surrounding tissue's ability to dissipate the heat. The numerous laser parameters such as the emission mode, the power density, and the time of exposure 
used for the procedure are also significant. Heating occurs as the laser energy is absorbed. At temperatures of approximately $600^{\circ} \mathrm{C}$, without any vaporization of the underlying tissue the proteins begin to denature. Coagulation refers to thickening of the liquid into a soft semi-solid mass producing irreversible damage to the tissue. This process by the contraction of the wall of the vessel produces the desirable effect of hemostasis.

Soft tissue edges can be "welded" together with a uniform heating to $70{ }^{\circ} \mathrm{C}$ to $80{ }^{\circ} \mathrm{C}$ where the layers adhere because of stickiness due to collagen molecule's helical unfolding and intertwining with adjacent segments [17].

Ablation is a process in which vaporization of the water within the target tissue occurs when the target tissue containing water is elevated to a temperature of $100^{\circ} \mathrm{C}$. There is a physical change of state, that is solid and liquid components turn into vapor in the form of smoke or steam. As soft tissue consists of a high percentage of water, excision of soft tissue begins at this temperature. The water component is vaporized but the apatite crystals and other minerals in dental hard tissue are not ablated at this temperature, and the subsequent jet of steam expands and then explodes the surrounding matter into smaller particles. This combination of steam and solids is then suctioned away. This micro-explosion of the apatite crystal is termed "spallation." The tissues get dehydrated and burned in the presence of air when the tissue temperature continues to be raised to about $200^{\circ} \mathrm{C}$. Carbon, as the end product, absorbs all wavelengths [17].

\section{PROBABLE INTRAOPERATIVE COMPLICATIONS}

1. Burns - An accidental injury by the laser energy can cause permanent scarring; but, this is very uncommon as the laser energy is carefully metered and contained.

2. Eye Damage - If you gaze or stare into the laser beam injury of the eyes is likely. To prevent this eye protection should be provided by means of protective eye glasses and it must be in place at all times when the laser is in use.

\section{Probable Short-Term Effects of Laser Dental Treatment}

1. Pain or a burning/itching sensation may occur after the treatment for a few days. A topical anesthetic or a local anesthetic can be used to block discomfort during the procedure but some discomfort may still be noticed.

2. For the first few days redness/Inflammation/swelling of the tissue might be noticed. The tissue adjacent to the procedure may feel "tight".

3. Wound Healing - Exuding of the tissue in the treated area will be present for a short time.

4. Allergies-Allergic reaction to the anesthetics used may be experienced.

5. Relapse/recurrence of a "fever blister" or Herpes Simplex Dermatitis may be noticed.

6. Tissue Hyper pigmentation-Transitory blackening of the tissue in the area especially in dark skinned people may be noticed.
7. Tissue Hypopigmentation-Lightening of the skin in the area - which can be long-lasting, may be noticed.

\section{Probable Long-term Complications of Laser Dental Treatment}

1. Scarring -the possibility of scarring exists. It is variable and frequently associated to genetic makeup. It can be reduced by cautiously following the appropriate aftercare instructions.

2. Tissue Pigment Changes - Soft tissue color and texture variations may occur. At the intersection of treated and untreated areas, a difference in color, texture, and/or thickness may appear.

3. Infection - There is a possibility of infection common to all surgical techniques. It can be reduced by proper postoperative care.

\section{The Advantages of Lasers for Soft Tissue Cutting are [18]}

i. The procedure requires minimal or no an aesthesia.

ii. They do not damage the dental hard tissues.

iii. Their cautious use does not injure the dental pulp.

iv. They can be used around dental implants because of low or no heat production.

v. They are antimicrobial.

vi. They eliminate endotoxins from root surfaces.

vii. There is increasing evidence that laser use may be helpful treatment for periodontal disease.

viii Laser equipment is considered state of the art by the common population, so patients are more accepting to its use in their treatment than of electrosurgery.

\section{The Disadvantages of Lasers for Soft-tissue Cutting are} [19]

1. The cost of laser is considerably higher than that of typical electrosurgery units.

2. Most of the procedures recommended for laser have similarity with those for the much less expensive electrosurgery.

3. Because of the impending danger of laser light, laser use necessitates a learning period and strict safety measures.

4. Protective glasses are required during its use as laser can cause eye damage.

5. As compared to electrosurgery, cutting with lasers usually is slower.

6. There is a charring flesh odor.

7. Some procedures are time consuming.

8. During laser use, combustible gases must be turned off.

9. Because of the presence of pathogens in pume, use of a high-filtration face mask is required. 


\section{CONCLUSION}

Plaque and calculus removal, coagulation, faster tissue ablation and healing, no or minimal pain, no or few sutures, instant sterilization, little tissue shrinkage and depigmentation are main factors favoring laser application in periodontics. On the other side, cost, safety issues, technical complexities, and lack of evidence-based studies about therapeutic effects and efficiencies are drawbacks of laser treatment.

\section{CONFLICT OF INTEREST}

The authors confirm that this article content has no conflict of interest.

\section{ACKNOWLEDGEMENTS}

Declared none.

\section{REFERENCES}

[1] Liboon J, Funkhouser W, Terris D. Comparison of mucosal incisions made by scalpel, $\mathrm{CO}_{2}$ laser, electrocautery and constantvoltage electrocautery. Otolaryngol Head Neck Surg 1997; 116: 379-85.

[2] Wilder-Smith P, Arrastia AM, Liaw LH, Berns M. Incision properties and thermal effects of thoursee $\mathrm{CO}_{2}$ lasers in soft tissue. Oral Surg Oral Med Oral Pathol Oral Radiol Endod 1995; 79: 685-91.

[3] Wilder-Smith P, Dang J, Kurosaki T. Investigating the range of surgical effects on soft tissue produced by a carbon dioxide laser. J Am Dent Assoc 1997; 128: 583-8.

[4] Wilder-Smith P, Arrastia AM, Liaw LH, Berns M. Incision properties and thermal effects of thoursee $\mathrm{CO}_{2}$ lasers in soft tissue. Oral Surg Oral Med Oral Pathol Oral Radiol Endod 1995; 79: 685-91.

[5] Pick RM, Colvard MD. Current status of lasers in soft tissue dental surgery. J Periodontol 1993; 64: 589-602.
[6] Perry D, Goodis H, White J. In vitro study of the effects of $\mathrm{Nd}$ :YAG laser probe parameters on bovine oral soft tissue excision. Lasers Surg Med 1997; 20: 39-46.

[7] Douglas N, Dederich NH. Laser/tissue interaction. Alpha Omegan 1991; 84: 33-6.

[8] Liboon J, Funkhouser W, Terris D. Comparison of mucosal incisions made by scalpel, $\mathrm{CO}_{2}$ laser, electrocautery and constantvoltage electro cautery. Otolaryngol Head Neck Surg 1997; 116: 379-85.

[9] Wilder-Smith P, Dang J, Kurosaki T. Investigating the range of surgical effects on soft tissue produced by a carbon dioxide laser. $\mathrm{J}$ Am Dent Assoc 1997; 128: 583-8.

[10] McKenzie AL. A three-zone model of soft-tissue damage by a $\mathrm{CO}_{2}$ laser. Phys Med Biol 1986; 31: pp. 967-83. doi:10.1088/00319155/31/9/003.

[11] Slot DE, Kranendonk AA, Paraskevas S, Van der Weijden F. The effect of a pulsed Nd:YAG laser in non-surgical periodontal therapy. J Periodontol 2009; 80: 1041-56.

[12] Lippert BM, Teymoortash A, Folz BJ, Werner JA. Wound healing after laser treatment of oral and oropharyngeal cancer. Lasers Med Sci 2003; 18(1): 36-42.

[13] Tucker D, Cobb CM, Rapley JW, Killoy WJ. Morphologic changes following in vitro $\mathrm{CO}_{2}$ laser treatment of calculus-ladened root surfaces. Lasers Surg Med 1996; 18: 150-6.

[14] Goldman HM. Subgingival curettage: a rationale. J Periodontal Res 1948; 19: 54-62.

[15] Caton JG, Zander HA. The attachment between tooth and gingival tissues after periodic root planing and soft tissue curettage. J Periodontol 1979; 50(9): 462-6.

[16] Midda M, Renton-Harper P. Lasers in dentistry. Br Dent J 1991; 170(9): 343-6.

[17] Coluzzi DJ. Fundamentals of dental lasers: science and instruments. Dent Clin N Am 2004; 84: 751-70.

[18] Coluzzi DJ. Lasers and soft tissue curettage: an update. Compend Contin Educ Dent 2002; 23: 1104-11.

[19] Cobb CM. Lasers in periodontics: a review of the literature. J Periodontol 2006; 77: 545-64.

Received: December 22, 2014

Revised: March 04, 2015

Accepted: March 10, 2015

(C) Kripal et al.; Licensee Bentham Open.

This is an open access article licensed under the terms of the Creative Commons Attribution Non-Commercial License (http://creativecommons.org/licenses/by-nc/3.0/) which permits unrestricted, non-commercial use, distribution and reproduction in any medium, provided the work is properly cited. 